\title{
Desempeño del profesor de Educación Intercultural Bilingüe: criterios evaluativos desde la voz del lof che
}

\author{
Desiderio Catriquir Colipan
}

Universidad Católica de Temuco, Temuco, Chile.

Email:dcatr@uct.cl

\begin{abstract}
Resumen: Este artículo aborda el problema de la ausencia de conocimiento acerca de criterios socio-étnico-educativos de evaluación del desempeño de los profesores de Educación Intercultural Bilingüe (EIB), que los miembros del lof che -comunidad parental- consideran relevante en escuelas situadas en comunidades mapunche en el centro-sur de Chile. El objetivo es aportar a la reflexión del posicionamiento interétnico que los miembros del lof che tienen respecto del desempeño del profesor de EIB, a fin de repensar los criterios de evaluación docente desde los requerimientos del lof che. La metodología de investigación se orienta por el paradigma sociocrítico que otorga apertura a la participación del lof che en el proceso investigativo, en tanto actores sociales que contribuyen a reorientar las prácticas escolares de los profesores EIB, y ofrecer criterios de evaluación que aporten a remirar el proceso de formación docente en contextos interétnicos e interculturales asimétricos.
\end{abstract}

Palabras clave: desempeño profesional, lof che, educación intercultural bilingüe, criterios evaluativos.

\section{The performance of intercultural bilingual education teacher: evaluation criteria from the perspective of the lof che's voice}

\begin{abstract}
This paper addresses the problem of the lack of knowledge about socio-ethnic- educational evaluation criteria on the performance of teachers of Intercultural Bilingual Education (IBE), which che lof members consider relevant in schools in schools located on mapunche community in south-central Chile. The aim is to provide analysis on interethnic positioning that che lof members have regarding the performance of EIB teachers, in order to rethink teacher's evaluation criteria viewed from che lof requirements. The research methodology is guided by the sociocritic paradigm that opens up to che lof participation in the research process, as social actors that can contribute to reorienting school practices of IBE teachers and provide evaluation criteria that can contribute to a re-envision of teacher's formation process in asymmetric interethnic and intercultural contexts.

Key words: professional performance, lof che, intercultural bilingual education, evaluative criteria.
\end{abstract}




\section{Desempenho do Professor de Educação Intercultural Bilíngüe: critérios de avaliação desde a voz do lof che}

Resumo: Este artigo aborda o problema da falta de conhecimento sobre critérios sócio-etno-educacionais de avaliação de desempenho dos professores Educação Intercultural Bilíngue (EIB), que os membros do lof che -comunidade parental- consideram relevante em escolas localizadas em comunidades mapunche no centro-sul do Chile. O objetivo é contribuir para a reflexão do posicionamento interétnico que os membros da etnia lof che têm em relação ao desempenho do professor da EIB, com a finalidade de repensar os critérios de avaliação docente desde as exigências do lof che. A metodologia da pesquisa é orientada pelo paradigma sócio crítico que dá abertura à participação do lof che no processo de pesquisa, como atores sociais que contribuem para redirecionar as práticas de ensino dos professores da EIB e fornecer critérios de avaliação que aportem um novo olhar para a processo de formação de professores em contextos interétnicos e interculturais assimétricos.

Palavras-chave: desempenho profissional, lof che, educação intercultural bilíngue, critérios de avaliação.

\section{Introducción}

El desarrollo de la Educación Intercultural Bilingüe (EIB) en Latinoamérica, impulsado por el movimiento social indígena, con apoyo del sector socialmente comprometido de la academia, ha incorporado lentamente la participación de las comunidades en los procesos educacionales escolares. En la mayoría de los casos, sólo cuando la EIB recibe el reconocimiento oficial del Estado, las comunidades contribuyeron en la formulación de propuestas educacionales de EIB y/o evaluando el desempeño docente. Sin embargo, esto ocurre desde la perspectiva de las normativas institucionales nacionales (López 2005).

En Chile, la EIB oficial comienza en la década de 1990, con participación de la academia socialmente comprometida, mediante la licitación de un proyecto piloto en EIB por el Ministerio de Educación, que introdujo la figura del Asesor Cultural ${ }^{1}$ en la escuela dando participación a la comunidad originaria en el contexto educacional escolar con presencia de niños y niñas mapunche ${ }^{2}$ en el centro sur de Chile.

Desde la perspectiva socio-histórica, el movimiento mapunche que emergió en la primera década del siglo XX como reacción a la política reduccional implementadas por los gobiernos entre 1881 y 1927, demandó la instalación de escuelas en territorios de comunidades mapunche, además de la enseñanza de la lengua mapunche (Foerster y Montecino 1988). Estas demandas no consideraban el rol que asumirían las autoridades tradicionales en la definición del modelo educacional que implementaría el Estado nacional (Durán et al. 1989; Comisión de Verdad Histórica y Nuevo Trato 2009; Durán et al. 2011). 
En Chile, desde el período pos ocupación territorial y reducción de la sociedad mapunche por parte del Estado chileno (1849-1927) y hasta la década de los 80, la política educacional nacional masificó progresivamente la instalación escuela y aplicó un modelo de castellanización y la homogenización lingüística y cultural de la sociedad mapunche (Guarda 2001; Durán y Ramos 1987). En todo este proceso y hasta la década de los ochenta las comunidades mapunche no tuvieron posibilidades de participación en las decisiones de educacional.

A partir de la década de los noventa, los estudios de antropología educacional y la pedagogía intercultural han develado el modelo educacional mapunche, distinguiéndose por lo menos cinco rasgos constitutivos (Catriquir y Durán 2007):

a. La interacción educativa o relación aprendizaje-enseñanza. Destaca la participación del enseñante, particularmente el kimche -sabios-, el kimün che -gente con saberes- y el kimpelu o aprendiz. Esta interacción está mediada por el kim, base del conocer y del saber, que pone en relación a actores diferenciados por sus condiciones específicas y fines del aprendizaje.

b. Contextos educativos, como el rukache o familia, incluyendo el entorno y las actividades productivas; espacios ceremoniales y simbólicos como los pewma -mensajes oníricos-, y los espacios introducidos por el movimiento social, tales como xawün o reuniones.

c. El campo contextual y el sociopolítico muestra la controversia intergeneracional actual: el movimiento social privilegió la incorporación de la población joven al sistema escolar pero aceptó en los años noventa un modelo restringido de EIB concebida desde los intereses del Estado. Se aprecia escasa vinculación entre los referentes del movimiento y los fütake che -ancianos-, aun cuando se advierten instancias en que opera el rakizuam -lógica de pensamiento- entre los fütake che que participan de los eventos sociales.

d. Principios educativos, el zapin zugu, proceso civilizatorio endógeno, que indica que todo puede y debe ser cultivado: el küme kimün -conocimiento o recto saber-; el küme gübam -orientación sabia-, que actúa para prevenir y/o corregir el comportamiento errado en relación al modelo de che; el küme rakizuam (recto pensamiento), que orienta el buen entendimiento, para que el che no entre en pekan zugu o asuntos incorrectos.

e. Métodos y estilos de aprendizajes, destacándose los orales imitativos, demostrativos y normativos. En este ámbito, se registra la lógica evaluativa de los aprendizajes y desempeños de los actores sociales en sus respectivos roles, dependiendo del sexo, la edad y las necesidades del küme mogen o la vida recta fundada en las buenas razones (Díaz 1996; Catriquir y Durán 2007). 
f. Fines de la interacción educativa, en la sociedad mapunche es deseable que las nuevas generaciones aprendan a ser che, saber vivir en el lof che y en la sociedad.

Las políticas educacionales impulsadas por el Estado desde inicios de la república se expresan en la continuidad colonial e invisibilización de la soberanía educacional de este pueblo mapuche. Por su parte, la política del movimiento mapunche pos ocupación del territorio desde la década de 1910 en adelante ${ }^{3}$, posesionó étnicamente a los líderes en demandas educacionales escolares al Estado, pero no configuró una política de alianza con sectores chilenos en el campo educacional que los situara con estrategias de negociación (Foerster y Montecino 1988). Una mayor explicitación del posicionamiento interétnico mapuche-estado nacional se dio a partir del acuerdo de Imperial, en la que el movimiento indígena se sitúa como tal y pone en la agenda política del retorno a la democracia la educación intercultural bilingüe.

En síntesis, la problemática educacional radica en la exclusión de la comunidad tradicional mapunche en los procesos de evaluación de las prácticas pedagógicas de docentes en escuelas situadas en los lof che. Situación que se mantiene, pese a que la sociedad tradicional mapunche posee modelos evaluativos para valorar procesos formativos de niños y niñas.

El supuesto en este artículo es que el conocimiento evaluativo mapunche puede contribuir a enriquecer los modelos evaluativos del desempeño docente en contextos interculturales; en particular de los profesores EIB formados en la Universidad Católica de Temuco (UCT) (UCT, 1992).

El objetivo de este artículo es describir estos criterios evaluativos, a fin de aportar a la reflexión del posicionamiento interétnico de los miembros del lof che respecto del desempeño del profesor de EIB. De esta manera, se busca aportar elementos que permitan repensar mecanismos de evaluación docente desde los requerimientos del lof che y considerarlos en procesos de formación de profesores en Educación Intercultural Bilingüe en la UCT.

El desarrollo de este artículo propone la siguiente organización argumentativa: un apartado discute el desempeño docente y las formas evaluativas concebidas en el marco del saber cultural mapunche; otro revisa el marco metodológico que explicita el contexto de investigación, en este caso el centro sur de Chile; un tercer apartado expone los resultados de la investigación; y por último, se presenta la discusión y conclusiones del estudio.

La pedagogía intercultural crítica, así como la ciencia intercultural que ha emergido en la última década (Aguado 2003) han posibilitado la visibilización y valoración del conocimiento educativo de los pueblos originarios; sin embargo, los modos de evaluar el desempeño docente en contextos interculturales sólo se vislumbra en la literatura pedagógica de la educación intercultural bilingüe. Al respecto nos preguntamos, cuáles son 
los criterios que el lof che considera al momento de evaluar el desempeño pedagógico de los profesores de educación intercultural y de qué modo el conocimiento de tales criterios puede contribuir a introducir mejoras en los proceso de formación docente en Educación Intercultural Bilingüe.

\section{Marco de referencias}

\section{Alcances conceptuales en torno al desempeño profesional del profesor}

En torno al desempeño profesional gravitan conceptos como profesión, práctica pedagógica, escenarios de actuación, estructura social y procesos de formación y cumplimiento de obligaciones inherentes a una profesión, cargo u oficio, en el marco de una estructura social (Imbernón, 1999).

Las investigaciones de Imbernón (1999), Pérez (1999) dieron un salto cualitativo en el campo docente, pasando de una concepción de profesor concebida como oficio o arte al de profesión. La profesión como campo de acción del profesor se amplía con la progresiva división del trabajo y la aspiración de al estatus de profesión de las ocupaciones de clases medias en el siglo XIX, principalmente en Inglaterra y Estados Unidos. En los países noratlánticos, la revolución industrial, la masificación de la escolarización y el desarrollo científico del siglo XIX constituirán las bases sociales y económicas de la demanda de mano de obra cualificada, a la vez que ilustrada en el dominio de la comunicación escrita y el cálculo, creando la necesidad de la profesionalización de la sectores sociales y educacionales (Llerena 2011; Marcelo 1999).

En Chile, la profesionalización docente se encuentra las primeras décadas de la república, con creación de Escuelas Normales e institutos pedagógicos. Estas instituciones permanecen hasta mediados de 1970. Luego, la formación de profesores tanto de primaria como secundaria forma parte de las universidades (Cox y Gysling 2009). Este tránsito institucional impulsó la profesionalización de los profesores (Ávalos, Cavada, Pardo y Sotomayor 2010).

En el campo conceptual, Imbernón (1999: 24) define la profesión docente como "el ejercicio de unas tareas de carácter laboral educativo al servicio de una colectividad, con unas competencias en la acción de enseñar, en la estructura de las instituciones en donde ejerce ese trabajo y en el análisis de los valores sociales”. Es decir:

Comporta un conocimiento específico pedagógico, un compromiso ético y moral y la necesidad de corresponsabilización con otros agentes sociales. Esto es así puesto que ejerce influencia sobre otros seres humanos y, por lo tanto, no puede ni debe ser una función meramente técnica de expertos infalibles. Además, cuenta también con un componente práctico, ya que los profesores y profesoras adquieren un cuerpo de conocimientos y habilidades especializadas 
durante un período de formación a lo largo de la vida profesional (Imbernón 1999: 24).

La profesión docente se distingue del oficio en cuanto aquella implica un proceso de formación institucionalizada acompañada de procesos de modernización de la educación vinculada a las reformas educacionales (Labaree 1999); en tanto el oficio docente tiene un componente de subjetividad e inter-subjetividad orientado a la manera a cómo en que se realiza un trabajo en cuanto producto (Alliaud y Antelo 2009).

El desempeño profesional del profesor refiere, por un lado, a la cualidad de la actuación del rol, que pone en juego el conocimiento profesional -conocimiento pedagógico- y las capacidades, habilidades y actitudes de actuación inteligente. Por otro lado, a un escenario de actuación signado por situaciones sociales complejas, nuevas, únicas e imprescindibles, propias de un entorno social complejo, dinámico y cambiante (Pérez, citado por Imbernón 1999), entre ellos los contextos interétnicos e interculturales.

Esta concepción del desempeño profesional concibe al profesor como un profesional práctico reflexivo, en cuanto experimenta sobre su propio quehacer, utilizando el conocimiento acorde a las situaciones contextuales y a la vez que indagador de nuevas alternativas educativas. Así, el conocimiento ya no es fin en sí mismo, sino un medio para mejorar el pensamiento y la toma de decisiones colectivas. Se constituye en un usuario del conocimiento a la vez que creador y recreador del mismo (Imbernón 1999).

\section{Pepiluwün zugu: el concepto de desempeño desde el mapunche kimün}

En el modelo educativo mapunche el "desempeño" se expresa los términos pepiluwün o pepilkawün, que refiere a la capacidad práctica de una persona, como manejar una herramienta. A la vez, se funda en la diada conocimiento y/o saber y en la aplicación práctica del conocimiento. Ello se aplica también a dominios de la medicina, al aprendizaje del textil, a la enseñanza y la capacidad de resolver un asunto (Erize 1960; Augusta 1916/ 1991).

En el campo formativo mapunche el aprendiz tiene la posibilidad de ejercitar la capacidad a desempañar pepilpepiltun: ensayar, probar como parte del proceso de aprendizaje, en el sentido de si alguien puede o sabe hacer algo. Es decir, la competencia se demuestra mediante acciones prácticas (Augusta 1991).

La idea de evaluación se expresa con los términos güneytun o güneltun que refiere a observar, notar, revisar con atención. Para evaluar y/ o examinar actitudes se usa el concepto ramtupiwken o mabüpiwken; para captar el pensamiento de otro se usa inazuam, entendido como reparar en, fijarse bien en lo que se dice (Augusta 1916/1991, Erize 1960).

El concepto de capacidad en mapunzugun se expresa con la palabra 
fitu o zitu que refiere al logro de una competencia, habilidad o destreza técnicas y/o cognitivas; literalmente, fituluwün refiere a lograr, conseguir una meta. Desde el dominio del conocimiento, la competencia se expresa con la categoría lingüística fitukimün, traducido como "entender, tener una idea clara de algo y de sus causas” (Augusta 1916/1991; Erize 1960).

La figura siguiente ilustra la relación entre los componentes del desempeño docente desde la lógica cultural mapunche.

\section{Figura 1. Componentes de un modelo de evaluación de competencias desde la lógica cultural mapunche.}

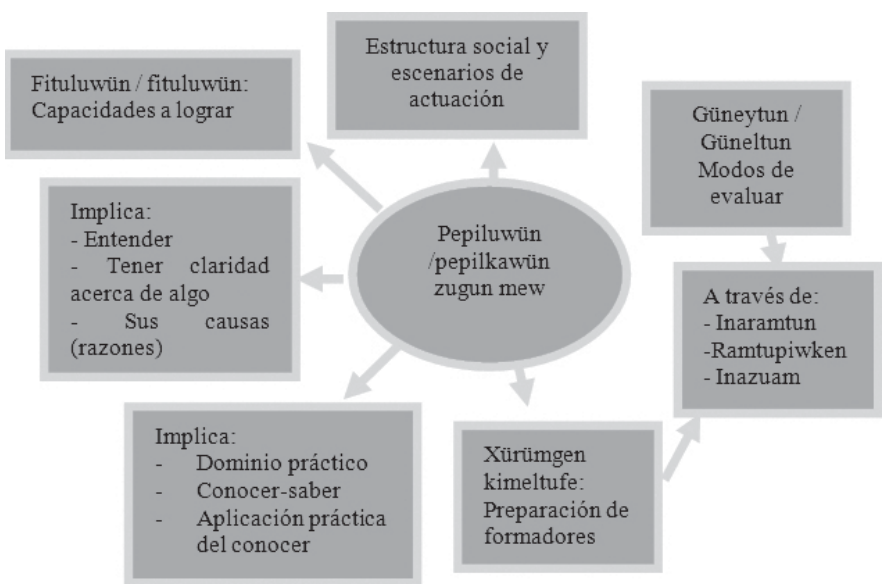

Lógica formativa de los docentes y su impacto en el desempeño de las prácticas pedagógicas en contextos interculturales

En el desempeño docente se identifican dos factores que influyen en las prácticas pedagógicas de los profesores: 1) la formación recibida en instituciones que no consideran la diversidad étnico-cultural y, 2) el perfil real actuado que el profesor de EIB moviliza en sus prácticas pedagógicas.

Otros factores que condiciona la acción docente en contextos interculturales es el patrón histórico monocultural y monolingüe de formación de los profesores en Latinoamérica. Ello explicaría su tendencia a preconcebir que la EIB no es posible de insertar en el sistema educacional tradicional y, menos aún, lograr transformaciones en el aula ni en el propio sistema educacional (Nucinkis 2006). La misma tendencia se advierte en docentes que recibieron capacitación en EIB (Rubio 2006), que no estarían logrando los niveles de desempeño acorde a su proceso de formación. 
En los docentes sin formación en EIB, se percibe que para éstos la EIB no es un requerimiento pedagógico sentido; sino más bien del movimiento indígena y de los científicos sociales comprometidos con la pedagogía crítica y la Educación Intercultural Bilingüe (Chiodi 1990; Citarella 1990; López 1999; Durán et al. 2007).

En Chile, Huenchullán (2007) advierte que el factor etario es gravitante en el desempeño de los docentes. En particular, Huenchullán (2007), citando a la OECD, señala que "los profesores antiguos" presentan dificultades para modificar sus prácticas pedagógicas y para adaptarse a los requerimientos de la EIB. Es decir, la distancia entre la formación recibida y el surgimiento e instalación de la EIB en las escuelas insertas en comunidades mapunche, tensiona los su habitus pedagógico monocultural docentes sin formación en EIB respecto de los requerimientos para re-crear nuevos habitus (Bourdieu 2007).

En el campo curricular, Huenchullán (2007: 23) señala que las generaciones de docentes de formación actual, tanto de EIB como los de formación tradicional, "adolecen de contenidos y metodologías que permitan" traducir la diversidad étnica, cultural y lingüística en contenidos de enseñanza, en el marco de relaciones de poder o contrapoder. Como indican Pérez y Martínez (2004), la práctica pedagógica implica siempre posicionamiento político, a la vez que técnico, del docente. Sin embargo, estos posicionamientos no siempre son compartidos por los docentes.

El análisis de Arratia (citado por Nucinkis 2007: 76) muestra que el desempeño pedagógico de los docentes de EIB egresados de los Institutos Pedagógicos, presentan hibridismo entre las "prácticas pedagógicas tradicionales y las nuevas propuestas educativas”. Es decir, la formación docente en EIB, no ha configurado perfiles de desempeño pedagógico que su sustente en paradigma intercultural, sino que se asienta en la tradición de la que buscan desprenderse.

Los perfiles actuados de desempeño de los docentes en contextos de EIB pueden ser analizados en relación a cuatro variables concurrentes: 1) pertenencia étnica y profesión, 2) comportamientos personales, 3) participación política y 4) factores histórico-personales.

Los perfiles de actuación socio-étnicos en contexto de EIB, permite identificar maestros de procedentes de comunidades rurales, "mestizos o blancos" y maestros de ascendencia indígena que han vivido procesos de enajenación cultural en las instituciones educativas nacionales. Cuando regresan a la comunidad representan conductas estructurales y culturales de la sociedad dominante, generando espacio de poder y prestigio social que antes no había en la comunidad. En otras palabras, el contacto interétnico escolar genera fenómenos psicosociales de blanqueamiento o auto-negación, situándose en un proceso transicional hacia el grupo de poder (BáezJorge y Rivera 1983). En el caso local mapunche se entiende como awigkamiento (Durán et al. 2011). 
Los estudios de Hevia e Hirmas (2005) muestran que el fenómeno socio-étnica de negación no es unívoco; mientras determinados docentes se ve afectado por la denominada vergüenza étnica, que los vulnerabiliza en su acción pedagógica, otro sector se ve dinamizando la tradición cultural de muchas comunidades, expresando compromiso con ellas y su cultura.

El desempeño docente, desde la perspectiva identitaria, se observa una tensión permanente entre la cultura de pertenencia y la de adquisición, tensión que se resuelve abandonando la defensa de los intereses comunitarios, en pro de mantener la posición adquirida en la dimensión política y cultural, mediante la "incorporación de normas y conductas de las clases dominantes” (Báez-Jorge y Rivera 1983: 273).

En la perspectiva de la participación política oficial, Baez-Jorge y Rivera (1983) muestran que los profesionales indígenas bilingües plantean demandas de modificación de la institución, que derivan desde la esfera oficial y no desde la conciencia étnica de los profesionales; siendo su meta la integración plena a posición de directivos de las esferas estatales.

Los estudios acerca el desempeño docente en general indica que los maestros fundan sus prácticas educativas en el imaginario pedagógico de la visión clásica en que se formaron, proyectado el modelo jerarquizado del conocimiento en el currículo escolar, y minorizando el estatus del conocimiento de los pueblos originarios (Hevia e Hirmas 2005).

En síntesis, la práctica pedagógica docentes, los contenidos y metodología implementadas en escuelas situadas en contextos interculturales expresa la vigencia de la tradición asimilacionista del pensamiento educativo postmoderno anclada en perspectiva coloniales, concibiendo el aula escolar como espacio pedagógico civilizador y respaldado en la normativa que determinan el idioma que se ha de usar en el aula intercultural (Hevia e Hirmas 2005).

El enfoque pedagógico intercultural aplicado a contexto escolares interculturales puede posibilitar el análisis de la lógica institucional dominante que determina acciones de carácter adaptativo y de reducción de la diferencia en lugar de asumirla como potencialidad y de re-posicionamiento étnico cultural de los docentes indígenas (Hevia e Hirmas 2005; López, 2005).

Los factores histórico-personales y profesionales son relevantes en el desarrollo docente en contextos de comunidades originarios, particularmente si éstos son descendientes de pueblos originarios. Por un lado, en la comprensión del sentido de los nuevos conceptos y propuestas pedagógicas; por otro, en la voluntad personal de adoptarlos e incorporarlos a sus formas de trabajo y, por último, "[...] si se sienten capacitados y comprometidos a operativizar las nuevas orientaciones en los procesos de enseñanza y aprendizaje” (López 2005:380). 
En este marco, el compromiso, la confianza con las comunidades, así como la historia personal y profesional del docente gatillan innovaciones en sus prácticas que impregnan todo su desempeño docente, su disposición a favorecer cambios curriculares, configurando en el aula un clima social y psicológico que redunda en el aprendizaje de los niños y niñas (López 2005).

El posicionamiento socio-étnico, es relevante en el desempeño docente; por un lado, deben demostrar que como profesores de lengua son hablantes de castellano a la vez que reconocen y valoran su propia lengua; por otro lado, son miembros de la misma comunidad. En efecto, el "éxito de estos docentes deviene de su historia personal y de su posicionamiento social y étnico” (López 2005: 383).

Este fenómeno de posicionamiento socio-étnico identitario de los docentes de ascendencia indígena y la valoración de la diferencia étnicocultural por parte de los docentes no indígenas podrían fundar práctica pedagógica de una educación social y culturalmente diferenciada y de calidad tanto en las nuevas generaciones de pueblos originarios como en los descendientes de la sociedad nacional.

\section{Desempeño docente en contextos interculturales y factores condicionantes}

La literatura revisada muestra ámbitos de desempeño laboral de los docentes de EIB, haciendo referencia a aspectos administrativos de mandos medios, especialmente “en el subsistema de educación indígena” y a nivel de escuelas primarias (Gigante 2007:214).

En el campo socio-educacional, Cuenca (2007) señala que el desempeño docente no sólo debe abordarse en el marco de la tarea pedagógicoeducativa, dentro o fuera del aula, sino además considerar las condiciones socio-profesionales, en el marco de la sociedad y del desempeño profesional. Aquí son centrales los conceptos de profesionalidad y profesionalismo, entendido el primero como prestigio, posición valorada del profesor en la sociedad, y el segundo como mejoramiento real de la tarea desempeñada (Hargreaves 1999, citado por Cuenca 2007).

Desde la perspectiva de la práctica pedagógica interactiva en el aula de escuelas situadas en contextos interculturales, permite entender el desempeño profesional de profesor en participación con estudiantes, directivos de escuelas y miembros locales, orientados por el principio de los derechos educativos y culturales de los pueblos originarios (Reyes y Vásquez 2008).

Por el contrario, como señalan Hevia e Hirmas (2005: 393), un modelo curricular positivista que entiende el "conocimientos como hecho objetivo”, oculta visiones racistas o de discriminación cultural. En este enfoque el desempeño docente se reduce a focalizar "contenidos, implementar pro- 
cedimientos y evaluar resultados", como mandato social de la escuela, evitando la reflexión crítica del docente frente a función social y cultural de currículo y la escuela, particularmente en contextos interétnicos e interculturales.

En este marco, se puede concluir con Moya (2007) que los maestros indígenas y no indígenas presentan dificultades para situar su desempeño como "artífices del proyecto histórico de los pueblos originarios", sintiéndose condicionados por las políticas públicas de los Estados nacionales y/ o por sus propias circunstancias personales expresadas en temor de enfrentar la práctica profesional (Inostroza 1997) evidenciando debilidades en el logro del perfil formativo ideal definido por las instituciones formadoras de docentes.

Factores sociales y técnicos que tensionan también el desempeño docente en contextos interculturales tales como: la expectativa castellanizante y la resistencia de los padres de familia, en desmedro de la lengua y los conocimientos propios (Baronnet 2008; Ramírez citado por Garcés 2006); falta de alianza entre miembros del movimiento indígena, docentes, científicos sociales, etc.; participación insuficiente de actores sociales indígenas en los diseños curriculares, su implementación y evaluación y, producción de materiales y, la necesidad de contar con un enfoque metodológico transcultural para la implementación de programas de EIB (Durán y Catriquir 2007).

Las metodologías transculturales, aunque incipientes en reflexiones interculturales, refieren a la posibilidad de establecer niveles de mediación de la experiencia, diferenciando el papel de los megarrelatos de las particularidades de los sucesos, favoreciendo procesos de comunicación entre las culturas involucradas en eventos pedagógicos (Durán y Catriquir 2007).

En Chile, el MINEDUC (2005) demostró tendencias opuestas en la visión que los miembros de la comunidad tienen acerca del desempeño docente en escuelas focalizadas en EIB. Por un lado, están los padres que evalúan positivamente la acción de los docentes en la escuela, especialmente el logro de aprendizaje de niños, reconociendo el esfuerzo por incorporar contenidos culturales mapunche en la enseñanza. Otros, en cambio, consideran estos logros como insuficiente.

Un tercer sector de comunidades mapunche se muestra dividido. Por un lado, quienes mantienen la lealtad cultural y lingüística, valoran positivamente la enseñanza de contenidos culturales; mientras que aquellos que profesan un credo evangélico, se muestran contrarios a la enseñanza de contenidos culturales mapunche. Este último caso se da en particular cuando el profesor y/o el director de la escuela es de ascendencia mapunche (Catriquir 2004; MINEDUC 2005).

En el campo de la planificación lingüística aplicado a la enseñanza Rubio (2006), demostró que institucionalmente existen instrumentos que 
permiten al docente adecuar su planificación lingüística a las necesidades específicas de los niños. Sin embargo, estos dispositivos no han sido adoptados como práctica docente, ni en la Dirección General de EBI. Esto, según Rubio (2006), se debe al insuficiente conocimiento del docente para planificar la enseñanza de idiomas en el aula, la carencias de recursos para la reproducción de los instrumentos de evaluación y la resistencia de parte de los docentes a romper la rutina escolar, y por último, carencia de dominio que los docentes tienen de las lenguas en contacto.

Los resultados de la EIB, según estudios MINEDUC (2005: 75) dejan ver problemas en el desempeño docente, especialmente en el uso de la lengua mapunche. Se registró, por ejemplo que de las clases "realizadas por los docente en el 70\% de ellas nunca usaron la lengua indígena, [cuando lo hacen] atienden fundamentalmente palabras sueltas, vocabulario básico y números”. Se observó también que conocimientos la historia del contacto, la organización social mapunche, la gramática de la lengua mapunche y el sistema de parentesco, aún n forman parte de las actividades pedagógicas de los docentes.

La literatura latinoamericana permite construir un cuadro de diez ámbitos de desempeño del profesor en contextos interculturales, tal como se aprecia en la tabla siguiente.

\section{Tabla 1. Ámbitos, campos de actuación socio-pedagógica y factores condicionantes del desempeño del profesor en contextos interculturales.}

\begin{tabular}{|c|c|c|}
\hline $\begin{array}{l}\text { Ambitos de } \\
\text { desempeño }\end{array}$ & $\begin{array}{l}\text { Campos de actuación } \\
\text { socio-pedagógica }\end{array}$ & Factores del desempeño \\
\hline $\begin{array}{l}\text { Interacción del } \\
\text { profesor EıB con } \\
\text { comunidad local } \\
\text { originaria }\end{array}$ & $\begin{array}{l}\text { Defensa de los contextos } \\
\text { comunitarios } \\
\text { Dinamización de la } \\
\text { tradicion cultural de la } \\
\text { comunidad } \\
\text { Compromiso con las } \\
\text { comunidades }\end{array}$ & $\begin{array}{l}\text { Dominio cultural } \\
\text { Perfil docente: } \\
\text { Pertenencia étnica y experiencias } \\
\text { La profesion = prestigio social } \\
\text { Comportamiento historico-personal = } \\
\text { verguenza etnica } \\
\text { E awingkamiento } \\
\text { Participación politica desde la conciencia }\end{array}$ \\
\hline \multirow{4}{*}{$\begin{array}{l}\text { Contenidos de } \\
\text { ensefanza [ámbito } \\
\text { curricular] }\end{array}$} & $\begin{array}{l}\text { Incorporación de la } \\
\text { diversidad étmica en la } \\
\text { educación }\end{array}$ & $\begin{array}{l}\text { Posicionamiento politico del profesor } \\
\text { Posicionamiento técnico del profesor }\end{array}$ \\
\hline & $\begin{array}{l}\text { Incorporacion de la } \\
\text { diversidad cultural }\end{array}$ & $\begin{array}{l}\text { Posicionamiento politico } \\
\text { Posicionamiento técnico }\end{array}$ \\
\hline & $\begin{array}{l}\text { Incorporación de la } \\
\text { diversidad lingaistica en } \\
\text { la enseñanza }\end{array}$ & $\begin{array}{l}\text { Formación docente } \\
\text { Practicas pedagógicas hibridas entre el } \\
\text { modelo tradicional y la propuesta ETB. }\end{array}$ \\
\hline & $\begin{array}{l}\text { Incorporación de } \\
\text { contenidos culturales } \\
\text { mapunche en la } \\
\text { enseñanza } \\
\text { Historia del contacto } \\
\text { Organización social } \\
\text { Sistema de parentesco } \\
\text { Gramatica de la lengua } \\
\text { mapuche }\end{array}$ & $\begin{array}{l}\text { Modelo curricular positivista (ve los hechos } \\
\text { objetivos sin visión critica ni consideración } \\
\text { de los contextos interculturales-interétnicos) } \\
\text { Curriculum democrático } \\
\text { Modelo kimeltuwan } \\
\text { Identidad étnica del docente } \\
\text { Modelo curricular asumido por la institución } \\
\text { Posicionamiento de credo religioso de los } \\
\text { padres }\end{array}$ \\
\hline $\begin{array}{l}\text { Evaluación de } \\
\text { aprendizajes }\end{array}$ & $\begin{array}{l}\text { Procedimientol de } \\
\text { evaluacion } \\
\text { Producción de } \\
\text { instrumentos de } \\
\text { evaluacion }\end{array}$ & $\begin{array}{l}\text { Modelo cumicular positivista (ve los hechos } \\
\text { objetivos sin vision critica ni consideración } \\
\text { de los contextos). }\end{array}$ \\
\hline
\end{tabular}




\begin{tabular}{|c|c|c|}
\hline \multirow{3}{*}{$\begin{array}{l}\text { Enfoques } \\
\text { curriculares y } \\
\text { metodológicos }\end{array}$} & $\begin{array}{l}\text { Modelo de conocimiento } \\
\text { usado en las practicas } \\
\text { pedagogicas (modelo de } \\
\text { kiman) } \\
\text { Metodologias de } \\
\text { enseñanza }\end{array}$ & $\begin{array}{l}\text { Apropiación del lenguaje académico } \\
\text { (jerarquizacion del conocimiento) } \\
\text { Papel histórico de la escuela: } \\
\text { Civilizador } \\
\text { Liberador } \\
\text { Nacionalizante } \\
\text { Transformador de relaciones }\end{array}$ \\
\hline & $\begin{array}{l}\text { Diferenciación étnica y } \\
\text { cultural (potencialidad } \\
\text { para las relaciones) }\end{array}$ & $\begin{array}{l}\text { Lógica institucional dominante } \\
\text { ¿Cómo el profesor rompe esta lógica y la } \\
\text { coloca a su favor? }\end{array}$ \\
\hline & $\begin{array}{l}\text { Operativización de } \\
\text { nuevas orientaciones en } \\
\text { procesos de enseñanza- } \\
\text { aprendizaje }\end{array}$ & $\begin{array}{l}\text { Experiencia historica-personal-social del } \\
\text { docente }\end{array}$ \\
\hline $\begin{array}{l}\text { Organizacióny } \\
\text { prácticas } \\
\text { pedagógicas }\end{array}$ & $\begin{array}{l}\text { Innovación en practicas } \\
\text { pedagógicas } \\
\text { Abordaje pedagógico de } \\
\text { actitudes racistas } \\
\text { Adecuación del } \\
\text { curriculum escolar }\end{array}$ & $\begin{array}{l}\text { Disposición a los cambios } \\
\text { Actitud reflexiva del docente } \\
\text { Modelo curricular asumido por la institución. } \\
\text { Insuficiente conocimiento del docente para } \\
\text { planificar la ensefianza del idioma. }\end{array}$ \\
\hline $\begin{array}{l}\text { Organización de } \\
\text { conocimientosy } \\
\text { prácticas culturales }\end{array}$ & $\begin{array}{l}\text { Valoración práctica de las } \\
\text { lenguas en contacto = } \\
\text { orientación de una } \\
\text { educación social y } \\
\text { cultural diferenciada }\end{array}$ & $\begin{array}{l}\text { Requerimientos del sistema } \\
\text { Posicionamiento social y émico del profesor } \\
\text { (miembro de un pueblo originario e identidad } \\
\text { colaborativa o se asume primero como } \\
\text { profesional). }\end{array}$ \\
\hline \multirow[b]{2}{*}{$\begin{array}{l}\text { Compromiso socio- } \\
\text { Étnico }\end{array}$} & $\begin{array}{l}\text { Capacidad critica y } \\
\text { autocritica. }\end{array}$ & Capacidad critica y autocritica del profesor \\
\hline & $\begin{array}{l}\text { Compromiso y artifice del } \\
\text { proyecto historico de los } \\
\text { pueblos originarios }\end{array}$ & $\begin{array}{l}\text { Posicionamiento emico y profesional de } \\
\text { formación (Moya 2007). }\end{array}$ \\
\hline $\begin{array}{l}\text { Alianza y redes con } \\
\text { organizaciones e } \\
\text { instituciones }\end{array}$ & $\begin{array}{l}\text { Alianza con los actores } \\
\text { sociales (movimiento } \\
\text { docente, cientificos } \\
\text { sociales, comunidades) }\end{array}$ & $\begin{array}{l}\text { Posicionamiento étnico-profesional } \\
\text { Formación docente para formar esas alianzas. } \\
\text { Posicionamiento de los miembros de la } \\
\text { comunidad frente a la EIB. }\end{array}$ \\
\hline $\begin{array}{l}\text { Participación } \\
\text { curricular de } \\
\text { actores tocales }\end{array}$ & $\begin{array}{l}\text { Participacion de los } \\
\text { actores en diseños } \\
\text { curriculares, su } \\
\text { implementación } \\
\text { Producción de } \\
\text { instrumentos de } \\
\text { evaluación y producción } \\
\text { de materiales de } \\
\text { enseñanza }\end{array}$ & $\begin{array}{l}\text { Expectativas de castellanizacion. } \\
\text { Resistencia de los padres respecto de las } \\
\text { lenguas. }\end{array}$ \\
\hline $\begin{array}{l}\text { Aprendizajes de los } \\
\text { nin̄os/as }\end{array}$ & $\begin{array}{l}\text { Fortalecimiento de la } \\
\text { identidad. } \\
\text { Aspectos curriculares: } \\
\text { aprendizaje del castellano. }\end{array}$ & $\begin{array}{l}\text { Posicionamiento de los padres frente a la EIB } \\
\text { Identidad emica del docente }\end{array}$ \\
\hline
\end{tabular}

Fuente: Construcción personal

\section{Marco metodológico del estudio}

El paradigma de base para esta investigación es el socio-crítico (Guba y Lincoln 2002; McLaren 1995). Este paradigma asume una realidad dinámica, condicionada por factores políticos, culturales, sociales, étnicos, económicos, de género, que conforman estructuras sociales. Este paradigma reconoce la inter-influencia sujeto-objeto, que se traduce en una relación mediatizada por los valores del investigador en el proceso de investigación.

\section{Diseño de investigación}

Esta investigación utiliza el Estudio de Casos Intrínseco e Instrumental (Stake 1998). Lo intrínseco se debe a que tiene como foco de aten- 
ción el desempeño pedagógico intercultural en profesores egresados de EIB, de una universidad en el centro Sur de Chile. El estudio de casos intrínseco se caracteriza por la presencia inherente de un conocimiento o experiencia, que lo hace particular de aprehender (Stake 1998). En este estudio, lo intrínseco está representado por la formación docente intercultural de la cual egresaron los profesores EIB que participan de esta investigación.

El diseño del estudio complementa el caso intrínseco con el estudio de caso instrumental. Éste se entiende como un caso complementario que tiene una vinculación con el objeto de estudio, y que permite una comprensión global del caso intrínseco (Stake 1998). En este sentido se incorporan distintos actores sociales como la comunidad tradicional: se incluye al Logko, ancianos que representan familias y, a miembros jóvenes del lof che. Cada una de estas instancias representa casos instrumentales que contribuyen a la comprensión del desempeño pedagógico intercultural.

Los casos seleccionados no son considerados como una muestra estadística representativa de una población, por el contrario, cada caso es estudiado y comprendido en su especificidad para luego proceder a la comparación entre ellos (Marradi et al. 2007).

\section{Contexto sociocultural de la investigación}

Esta investigación se sitúa en el contexto cultural y geográfico en el centro sur de Chile, escenario marcado por relaciones interétnicas e interculturales entre la sociedad mapunche y la sociedad chilena, y en el cual la escuela misional y pública ha tenido un papel central en la definición de las relaciones interculturales.

Los territorios ancestrales en las que habitan las comunidades mapunche se caracterizan actualmente por la coexistencia de formas organizativa: por un lado, la comunidad tradicional lof che y/o del kiñelmapu; por otro lado, la comunidad jurídica indígena, definida por la legislación indigenista de Chile -Ley N¹9.253 (Corporación Nacional de Desarrollo Indígena 1993).

Las comunidades mapunche o lof che en que se insertan las escuelas consideradas en esta investigación, exhiben pérdida de la lengua propia (el mapunzugun) en la generación infantil, en tanto que, en la generación adulta joven (treinta a cuarenta y cinco años) hay matices de bilingüismo con presencia mayoritaria de monolingües de castellano, aun cuando excepcionalmente algún niño es bilingüe mapunzugun-castellano.

Las escuelas presentes en las comunidades en que se desempeñan profesores de EIB son rurales incompletas (con niveles de primero a sexto año de primaria); otras son completas (primero a octavo año de 
primaria). Según el número de docentes son uni y bi-docentes.

Las comunidades mapunche viven en contextos interétnicos e interculturales. En estos contextos las comunidades mapunche expresan dos tendencias frente al papel de la escuela y respecto de la incorporación de la dimensión intercultural en el ámbito educacional. Los estudios de Catriquir (2004) y MINEDUC (2005) indican que el sector mapunche que ha optado por la corriente desarrollista, plantea dudas respecto de si la escuela en el pasado quitó a los mapunche su propia lengua cómo es que hoy pretende enseñarla; en tanto, el sector mapunche que representa la corriente cultural endógena, valora positivamente que la escuela enseñe la lengua y los conocimientos mapunche. Es en este sector sociocultural que busca develar los criterios de evaluación del desempeño del profesor EIB.

La literatura consultada acerca de la participación de las comunidades indígenas en procesos evaluativos de EIB, nos remite particularmente a Bolivia. Su frecuente referencia en este estudio no tiene sentido de comparación, sino la disponibilidad de fuentes a las que se tuvo acceso.

\section{Resultados del estudio}

Los resultados del estudio de criterios de evaluación del desempeño del profesor en EIB coinciden con aquellos ámbitos que subyacen en la literatura latinoamericana, que sirven de marco de referencia criterial para evaluar el desempeño docente del profesor EIB. En este sentido, el análisis, diferencia aquellas actuaciones socio-pedagógicas logradas de aquellas no alcanzadas en el desempeño del profesor EIB, desde la perspectiva del lof che o la comunidad tradicional mapunche.

\section{Evaluación del desempeño socio-pedagógico del profesor EIB desde la voz del lof che según criterios de logros socio-pedagógicos}

En este apartado se registran cinco ámbitos de desempeño del profesor EIB, a saber: 1) Participación de la comunidad, 2) Enseñanza de conocimientos tradicionales, 3) Capacidad de gestión del profesor intercultural, 4) Enseñanza y aprendizaje del mapunzugun, y 5) Preparación para la enseñanza media, como se indica en la tabla siguiente: 


\section{Tabla 2. Ámbitos y criterios de desempeño del profesor de EIB que el lof che valora como logros relevantes.}

\begin{tabular}{|c|c|c|}
\hline $\begin{array}{l}\text { Ámbito de } \\
\text { evaluación }\end{array}$ & $\begin{array}{l}\text { Criterio de desempeño } \\
\text { de actuación socio- } \\
\text { pedagógica }\end{array}$ & Factores condicionantes del desempeño \\
\hline $\begin{array}{l}\text { Participación de } \\
\text { la comunidad }\end{array}$ & $\begin{array}{l}\text { Gestión curricular. } \\
\text { Organización de talleres }\end{array}$ & $\begin{array}{l}\text { Apertura del profesor hacia la comunidad mapunche. } \\
\text { Liderazgo comunitario. } \\
\text { Conocimiento cultural mapunche. }\end{array}$ \\
\hline $\begin{array}{l}\text { Enseñanza de } \\
\text { conocimientos } \\
\text { tradicionales }\end{array}$ & $\begin{array}{l}\text { Contenidos tradicionales } \\
\text { mapunche } \\
\text { Investigación en } \\
\text { contexto comunitario }\end{array}$ & $\begin{array}{l}\text { Vigencia de conocimientos y prácticas culturales en } \\
\text { la comunidad. } \\
\text { Vinculación pedagógica del profesor realiza entre los } \\
\text { nimos y las generaciones adultas. }\end{array}$ \\
\hline $\begin{array}{l}\text { Capacidad de } \\
\text { gestión del } \\
\text { profesor } \\
\text { intercultural }\end{array}$ & $\begin{array}{l}\text { Gestión de necesidades } \\
\text { individuales }\end{array}$ & $\begin{array}{l}\text { Liderazgo de gestión intermediación comunidad - } \\
\text { instituciones nacionales. } \\
\text { Liderazgo administrativo y obtención de recursos } \\
\text { para la escuela. }\end{array}$ \\
\hline $\begin{array}{l}\text { Enseñanza y } \\
\text { aprendizaje del } \\
\text { mapunzugun }\end{array}$ & $\begin{array}{l}\text { Enseñanza del } \\
\text { mapunzugun } \\
\text { Aprendizaje del } \\
\text { mapunzugun }\end{array}$ & $\begin{array}{l}\text { Dominio de la lengua mapunche (favorece en la } \\
\text { enseñanza y aprendizaje de esta lengua) } \\
\text { Dominio elemental o ningún dominio del } \\
\text { mapunzugun. } \\
\text { Visibilización identitaria cultural del profesor de EIB. }\end{array}$ \\
\hline $\begin{array}{l}\text { Preparación del } \\
\text { estudiante para } \\
\text { la enseñanza } \\
\text { media }\end{array}$ & $\begin{array}{l}\text { Ingresar a la enseñanza } \\
\text { media. } \\
\text { Niveles de exigencias. } \\
\text { Identidad étmico-cultural } \\
\text { delos alumnos. }\end{array}$ & $\begin{array}{l}\text { Proyección de los niños hacia la educación } \\
\text { secundaria fuera de la comunidad. } \\
\text { Identidad émica del profesor, que la proyecta y } \\
\text { afirma en los niños para enfrentar la educación } \\
\text { secundaria. }\end{array}$ \\
\hline
\end{tabular}

Fuente: Construcción personal.

A continuación se proponen algunas observaciones respecto de cada uno de los ámbitos enumerados.

\section{1) Ámbito de participación de la comunidad}

La participación que los miembros de la comunidad mapunche han tenido en la gestión curricular, como es la contribución en la elaboración del Proyecto Educativo Institucional (PEI), y los Planes y Programas Propios se concibe como un criterio relevante en del desempeño del profesor EIB. Se señala por ejemplo: “[...] me incorporé al trabajo de aula [...], se logró establecer el PEI intercultural, actualmente tenemos planes y programas propios en la escuela hasta sexto básico” (Comunidad mapunche 2: 9).

Otras formas de participación de los miembros de la comunidad son los talleres organizados por el profesor intercultural favoreciendo vínculos más estrechos entre los apoderados: “...el año pasado se hicieron talleres acá, y sería bueno que siguieran haciendo. Porque así trabajamos todos y uno se integra más. Los talleres fueron orientados a la familia” (Comunidad mapunche 2:12). 
La participación de la comunidad en actividades realizadas por el profesor ha permitido mantener aspectos de la cultura mapunche: “...la comunidad está toda conforme porque en esto nos ha levantado, porque estaba como perdida la tradición y ahora está volviendo” (Comunidad mapunche 6: 4).

En la participación de la comunidad se aprecian dos aspectos que intervienen: la enseñanza de conocimientos tradicionales y la capacidad de gestión del profesor intercultural.

2) Enseñanza de conocimientos tradicionales

Los miembros de la comunidad valoran la enseñanza de contenidos tradicionales mapunche, y que los niños aprendan conocimientos tradicionales y puedan utilizarlos en su vida cotidiana, tales como: alimentación, artesanía, propiedades de plantas medicinales, entre otros. “[...] acá está muy vivo todavía lo que es la artesanía, el telar, el consumo de las yerbas medicinales. La mayoría de los chicos sabe para qué es buena una yerba. En los alimentos: el muday, el milcao" (Comunidad mapunche 2: 23).

Para el aprendizaje de éstos contenidos el profesor solicita que los alumnos y las alumnas realicen investigaciones en el contexto de la comunidad, cuyo objeto de estudio son contenidos que forman parte de las prácticas tradicionales del pasado:

[...] los niños llegan con tareas que el profesor le da como investigación, qué era lo antiguo, cómo se nombraba, o cómo vivía la gente antes. Eso lo están trabajando ellos, a lo mejor no ciento por ciento, pero están tomando ese trabajo [...] (Comunidad mapunche 3: 23).

3) Capacidad de gestión del profesor intercultural

La capacidad de gestión del / la docente intercultural, es reconocido positivamente como desempeño pedagógico por los miembros de la comunidad: "[...] todo eso yo le agradezco a ella, ella hizo trámites que yo no puedo hacer, ojala que lo pueda hacer con los otros también” (Comunidad mapunche 4:1).

La capacidad de gestión ha permitido que el docente ayude a personas de la comunidad: " $[\ldots]$ ha encontrado más ayuda, a la comunidad también le ha llegado ayuda, bueno que él conoce más también” (Comunidad mapunche 4: 2). También el docente ha gestionado recursos materiales para la escuela: "[...] él ha conseguido hartas cosas que no había aquí en la escuela [...] implementos deportivos: mesas de pimpón, colchonetas” (Comunidad mapunche 4:3).

4) Enseñanza y aprendizaje del mapunzugun 
En la enseñanza del mapunzugun, los miembros de la comunidad reconocen que el profesor realice ejercicios de traducción del mapunzugun al castellano: “[...] la profesora empezó a escribir en mapunzugun y al lado en castellano [...] y mi hijo aprendió muy bien. Por lo menos: mari/diez, pataca/cien [...] Así ellos se manejan muy bien” (Comunidad mapunche 1: 11).

Las personas de la comunidad sugieren que los profesores deben conocer y practicar el mapunzugun, a fin de que la enseñanza sería más efectiva: “[...] la profesora PX habla en mapuche, y los demás también tienen que empezar a aprender [...]. Por ejemplo, la profesora Berta también lo escuchó pero muy poco” (Comunidad mapunche 1: 12).

El aspecto más valorado por los miembros de la comunidad en el aprendizaje del mapunzugun, es la capacidad de realizar discursos públicos. Así, se reconoce como especialmente relevante que el niño mapunche pierda el miedo o la vergüenza a expresarse en mapunzugun: "[...] la gente quiere que el niño que aprendió mapunzugun, lo converse, hable adelante de personas, que salga la vergüenza para hablar [su propia lengua], yewentukunoalu egün, eso lo piden los apoderados" (Comunidad mapunche 1: 16).

La comunidad reconoce, por otro lado, que la enseñanza del mapunzugun representa una debilidad del docente, dado que éste no domina el mapunzugun: "[...] claro de repente le habla a los niños pero no un ciento por ciento. Que le nombre alguna cosa con detalle, que significa en mapuche, le falta que hable en su propia lengua mapuche” (Comunidad mapunche 3: 7).

Para los entrevistados, la enseñanza del mapunzugun en las escuelas debería tener la misma importancia que la enseñanza del inglés: "[...] todo lo que tendría que seguirse es el mapunzugun, eso es lo importante, a medias que sepan. Tal como se enseña el inglés, el mapuche también tendría que enseñarse” (Comunidad mapunche 4: 4).

Los comunidad manifiestan que la enseñanza del mapunzugun debería responder a contextos comunitarios específicos, respetando diferencias lingüísticas de otras comunidades: “[...] lo que hemos visto es que tendría que enseñarse la lengua de acá, la que se práctica acá, la que se habla acá” (Comunidad mapunche 4: 11).

Además, los miembros de la comunidad manifiestan que el docente intercultural, en términos generales, tiene un dominio elemental del mapunzugun: "[...] yo no puedo decir nada, porque ella sabe hablar en mapuzugun y lo habla bien claro también” (Comunidad mapunche 1: 15).

Los entrevistados señalan que el docente intercultural es capaz de sostener diálogos con apoderados y alumnos/as: “[...] ahí se nota la 
diferencia, con la profesora PC [...] él demuestra más lo mapuche, porque él recibe a los apoderados y a los niños en mapuche” (Comunidad mapunche 7:12).

\section{5) Preparación para la enseñanza media}

Los miembros de la comunidad tradicional reconocen que el docente intercultural prepare a alumnos y alumnas para ingresar a la enseñanza secundaria, en dos aspectos: uno para enfrentar con éxito el currículum educacional oficial y, el otro, para asumir su identidad étnico-cultural de modo proyectivo., que le asegure éxito en la enseñanza secundaria: “...sí eso lo veo yo también, tienen más cambio y están más preparados también, yo veo por mi hija, cómo va ella” (Comunidad mapunche 1: 6).

En el ámbito de la práctica curricular escolar la comunidad tradicional da importancia los niveles de exigencia con que la docente intercultural desempeña su labor y, en consecuencia, las calificaciones son congruentes con el esfuerzo realizado por los alumnos/as: “...ella no regala las notas, eso me gusta mucho de la profesora. El niño que se esfuerza tiene la nota que se merece" (Comunidad mapunche 1: 4).

En relación a la proyección de la identidad étnico-cultural los miembros de la comunidad tradicional aprecian la acción del profesor EIB, en el sentido de que los niños otorgan valor voluntariamente a su lengua originaria más allá del medio local: “allá [en el liceo] hablan en mapuche, le están haciendo empeño para que ellos puedan hablar, no olvidar la lengua, pero allá no hay profesores que le van a enseñar eso" (Comunidad mapunche 1: 7; 3:1).

\section{Evaluación del desempeño pedagógico del profesor EIB desde la voz del lof che según criterios no logrados en el desempeño socio-pedagógico}

En este apartado se registran cinco ámbitos de desempeño que los miembros del lof che consideran de importante dominio en el desempeño del profesor EIB, a saber: 1) fortalecimiento de la EIB, 2) trabajo en equipo en la comunidad, 3) trabajo en terreno del profesor EIB, 4) fortalecimiento del inglés como lengua extranjera, y 5) formación de los niños para la interacción cotidiana con el mundo no visible como con los miembros de la comunidad. Estos ámbitos se presentan en la tabla siguiente: 


\section{Tabla 3. Ámbitos y criterios de desempeño del profesor de EIB que el lof che considera relevantes.}

\begin{tabular}{|c|c|c|}
\hline $\begin{array}{l}\text { Ámbito de evaluación } \\
\text { del desempeño }\end{array}$ & $\begin{array}{l}\text { Criterio de desempeño } \\
\text { de actuación socio- } \\
\text { pedagógica }\end{array}$ & $\begin{array}{l}\text { Factores condicionantes del } \\
\text { desempeño }\end{array}$ \\
\hline $\begin{array}{l}\text { Fortalecimiento y } \\
\text { liderazgo en la EIB }\end{array}$ & $\begin{array}{l}\text { Ausencia de la. EIB en el } \\
\text { aula } \\
\text { Liderango pedagógico }\end{array}$ & $\begin{array}{l}\text { Falta de involucramiento con la comunidad. } \\
\text { Falta de liderango en BIB. } \\
\text { Falta de compromiso con la EIB. }\end{array}$ \\
\hline $\begin{array}{l}\text { Trabajo en equipo con } \\
\text { la comunidad }\end{array}$ & $\begin{array}{l}\text { Fortalecimiento del trabajo } \\
\text { en equipo. } \\
\text { Generación de instancias } \\
\text { de comunicación. } \\
\text { Empoderamiento del papel } \\
\text { del profesor de EIB. } \\
\text { Estrategias para una } \\
\text { comunicación amplia con } \\
\text { la comunidad. }\end{array}$ & $\begin{array}{l}\text { Carencias de trabajo en equipo con los } \\
\text { profesores de la escuela. } \\
\text { Falta de interacción con la comunidad local } \\
\text { mapunche en equipos de trabajo. } \\
\text { Falts de estrategias de comunicación amplia } \\
\text { con la comunidad mapunche. } \\
\text { Posicionamiento extemo a la comunidad } \\
\text { dificulta la comunicación. }\end{array}$ \\
\hline Trabajo en terreno & $\begin{array}{l}\text { Intervención en terreno } \\
\text { mediante la BIB. } \\
\text { Conocimiento cultural de } \\
\text { las ceremonias culturales } \\
\text { mapunche. }\end{array}$ & $\begin{array}{l}\text { Falta de empoderamiento de la EIB. } \\
\text { Carencia de intervención en la comunidad } \\
\text { mapunche mediante la.EIB. }\end{array}$ \\
\hline $\begin{array}{l}\text { Fortalecimiento del } \\
\text { inglés como lengua } \\
\text { extranjera }\end{array}$ & $\begin{array}{l}\text { Fortalecer el inglés como } \\
\text { lengus extranjers. }\end{array}$ & $\begin{array}{l}\text { Requiere una visión de la realidad actual, a } \\
\text { fin de asegurar el éxito de los estudiantes } \\
\text { mapunche en la educación secunderia. }\end{array}$ \\
\hline $\begin{array}{l}\text { Formación de los niños } \\
\text { paralainteracción } \\
\text { cotidiana }\end{array}$ & $\begin{array}{l}\text { Saludar a los lugares } \\
\text { (espacios ecológicos) } \\
\text { cuando se entre en ellos. } \\
\text { Saludo entre personss. }\end{array}$ & $\begin{array}{l}\text { Falta de vínculo con la comunided mediado } \\
\text { por el conocimiento local. } \\
\text { Falta de conocimiento del modelo de } \\
\text { educación tradicional mapunche, orientado } \\
\text { hacia la formación de personss. }\end{array}$ \\
\hline
\end{tabular}

Estos ámbitos son percibidos como desempeños no logrados por parte del profesor EIB en la perspectiva del lof che, arrojando luces para tener en cuenta en la formación docente en EIB en contextos interétnicos e interculturales. A continuación, desarrollamos cada uno de ellos.

\section{1) Falta de fortalecimiento y de liderazgo en la EIB}

La comunidad local demanda que el profesor/a intercultural incorpore con mayor énfasis presencia de la EIB en el aula, dada su condición de profesional que le otorga competencias para hacerlo: “[...] de acuerdo a la formación, tiene ciertas competencias, pero le falta involucrar EIB la sala [...]" (Comunidad mapunche 2: 28). Al profesor/a no se le ve liderando la acción pedagógica en EIB, sino que delega toda la responsabilidad en la Asesora Cultural: "[...] el tema EIB me lo cede a mí, para que lo trabaje yo como asesora. Falta que [el profesor/a] se involucre más con el tema EIB” (Comunidad mapunche 2: 29). 


\section{2) Fortalecimiento del trabajo en equipo}

El trabajo en equipo es un criterio relevante de los miembros de la comunidad para evaluar el desempeño docente EIB, particularmente cuando éste lidera procesos. En tal sentido: “[...] si es algo cultural, tienen que participar todos los profesores, no solamente la lamgen [hermana biológica y/o social], ellos tienen que trabajar en conjunto, apoyarse" (Comunidad mapunche 1: 13).

Asimismo, el profesor EIB debe configurar equipo de trabajo con los miembros de la comunidad local, especialmente con quienes poseen el conocimiento tradicional. Al respecto se indica: [...] y sí ella no sabe bien lo mapuche [...], ella puede pedir ayuda [...], hay personas adultas que sí saben y le pueden enseñar, eso es lo que falta en ella (Comunidad mapunche 1:13).

El trabajo en equipo implica que el docente intercultural genere instancias de acercamiento hacia personas de la comunidad tradicional. La insuficiente comunicación educacional del profesor EIB con la comunidad mantiene a ésta en un papel de espectadora, sin posibilidades de compartir el conocimiento de la lengua mapunche o reguardar la educación que reciben sus nuevas generaciones en la escuela.

En ocasiones, los miembros de la comunidad no están informados de que el docente tenga formación en Educación Intercultural. Ellos indican que:

[...] tal vez en alguna reunión ella, podría decir: [...] yo estoy haciendo clases de interculturalidad y, yo soy la profesora. Y si necesita algún tipo de ayuda, los apoderados sabemos hablar el mapunzugun, quizás no tanto como en el pasado [...] pero se sabe (Comunidad mapunche 7: 9).

La comunidad tradicional percibe que la gestión del profesor de EIB no sólo debe considerar la participación de los padres y apoderados, en cuanto que figura institucional mandatada por MINEDUC, sino debiera generar estrategias para una incorporación amplia de la comunidad, o lof che, más allá del Centro de Padres y Apoderados: “[...] el profesor tendría que llegar al resto de las personas, no sólo a los apoderados que tienen mayor participación porque tiene a sus hijos estudiando, sino también a los que no lo son” (Comunidad mapunche 4: 10).

\section{3) Falta de trabajo en terreno}

La comunidad considera que el desempeño del profesor EIB requiere mayor intervención en terreno a través de la EIB: “[...] la profesora le falta involucrarse más con la EIB, y con la comunidad, con organizaciones, con las comunidades indígenas” (Comunidad mapunche 2: 10). 
La comunidad espera que el docente se empodere del contexto comunitario, apelan a una pedagogía en terreno: "[...] porque he conocido a otros docentes que han salido de su misma universidad y sé que trabajan en terreno, se apoderan del asunto, se apoderan de su comunidad. Me gustaría eso también en esta comunidad” (Comunidad mapunche 2: 11).

La comunidad considera que las ceremonias culturales realizadas en la escuela es el espacio de participación del docente EIB y no asumir un papel espectador: "[...] no ha ayudado a organizar el We xipantu, sólo ha compartido con nosotros. Y no sé hasta donde ella sabe [...] porque uno tiene que saber para poder realizar algo mapuche” (Comunidad mapunche 31: 6).

4) Fortalecimiento del inglés como lengua extranjera

La informante señala que uno de los aspectos que requiere de mayor atención de parte del docente es fortalecer la lengua extranjera inglés, orientado al éxito escolar de los niños en otros establecimientos, en cuanto que exigencia del currículum nacional:

[...] para mí como apoderada creo que falta más potenciar el inglés, porque después los niños salen desde acá y se van a otros colegios. Yo vengo desde afuera y, allá en los colegios desde kínder les están enseñando inglés a los niños (Comunidad mapunche 2: 8).

En el marco del mundo global e informatizado, algunos miembros de la comunidad buscan la inserción de estas nuevas generaciones en ella:

[...] el inglés es importante afuera, mi hijo lo saque de acá y quedó repitiendo por no saber nada de inglés. No debemos dejar de lado eso de rescatar la cultura, pero viéndolo más claro es importante el inglés [...], hoy en día estamos avanzando tecnológicamente y cada vez se van haciendo estudios distintos, ¿̇y sin el inglés...? En todos lados, está el inglés (Comunidad mapunche 2: 17; 2: 20).

5) Formación de los niños para la interacción cotidiana

El saludo es una de los aspectos culturales altamente por los miembros de la comunidad, ya que es signo de preocupación y respeto por el otro, por lo tanto los niños deberían saludar al momento de ingresar a un lugar: “[...] que conozca su origen, y que salude, y pregunte ¿cómo está? Un joven de repente llega a una casa: 'hola', no me dice ni cómo esta, cómo está tal persona, esa no es la forma” (Comunidad mapunche 1: 18).

El saludo en mapunzugun si bien es una responsabilidad compartida entre profesor y comunidad, es aquel que debiera solicitar el apoyo para fortalecer este tipo de contenidos actitudinales: “[...] él no ha llamado a reunión, para decir qué es lo que necesita. El respeto a los mayores, es eso lo que necesitamos, muchas veces los niños no saben ni saludar" (Comunidad mapunche $4: 6$ ). 


\section{Discusión y conclusiones}

La literatura acerca del desempeño docente de los profesores en escuelas situadas en contextos interculturales e interétnicos muestra un conjunto de ámbitos de desempeño docente que se asocian a factores que posibilitan y/o dificultan el desempeño de los profesores. Esta característica del desempeño está presente tanto en profesores que han recibido formación en instituciones monoculturales como aquellos que han sido formados en programas de educación intercultural, de modo regular o a través de capacitaciones (Duran et al. 2011).

Los ámbitos de desempeño docente registrados en la literatura latinoamericana son coincidentes con el contexto local chileno en cuanto que el desempeño del profesor refiere a la enseñanza de saberes culturales y al aprendizaje de los niños, que se visualiza como un factor importante del desempeño, a la vez que limitante cuando el profesor EIB carece del conocimiento cultural originario. Una situación similar ocurre con el aprendizaje de la lengua mapunche, pues dependerá del nivel de dominio lingüístico del profesor EIB (Rubio, 2006)

En el campo de la identidad étnica, se observa que esta tiene incidencia gravitante en el desempeño docente, especialmente cuando se trata de abordar conocimientos culturales de los pueblos originarios. Así, según el grado de asunción de la identidad, el profesor podrá o no abordar la enseñanza de los conocimientos originarios, especialmente cuando los niños expresan vergüenza cultural y/o se avergüenzan de sus conocimientos y/o de su grupo social.

Si bien existen experiencias de participación de miembros de comunidades mapunche en aspectos curriculares debido a la apertura de algunos profesores EIB hacia las comunidades, en otros casos el profesor EIB aparece como espectador de las prácticas culturales de la comunidad. En tal sentido el criterio evaluativo del desempeño de la comunidad tradicional requiere que el profesor/a EIB se empodere de este modelo educacional y lo practique activamente tanto en el aula como en la comunidad. Esta experiencia es lejana a algunas prácticas educativas en escuelas interculturales registradas por López (2005) en Bolivia.

En tal sentido el profesor EIB requiere de metodología transcultural (Durán y Catriquir 2007) para favorecer un desempeño docente acorde a los criterios que demanda el contexto escolar y comunitario mapunche en situaciones de relaciones interétnicas e interculturales complejas.

Desde el punto de vista de la soberanía educacional, se aprecia que algunos miembros de la comunidad mapunche conciben que la evaluación del desempeño docente del profesor de EIB -y/o del profesor en generalen el marco de la comunidad, le corresponde al centro de padres y apoderados. Los logko sin embargo, no tienen esta postura. 
En este trabajo hemos realizado una aproximación exploratoria a las comunidades mapunche tradicional o lof che a fin de identificar criterios de evaluación del desempeño docente de los profesores de educación intercultural. Sin embargo, se hizo referencia a los modelos propios de evaluación de los desempeños, que en mapunzugun se expresan con la palabra pepiluwün, concepto que refiere a un conocimiento para un saber hacer.

Este trabajo podrá constituir base para futuras investigaciones en las que la comunidad tradicional puede participar, por un lado en cuanto que fuentes de conocimientos y por otro, como proceso formativo que le permita revitalizar paulatinamente su soberanía educacional en cuanto que patrimonio cultural.

A partir de estos resultados, surgen nuevos interrogantes acerca de cómo perciben los profesores de EIB los criterios con que miembros del lof che evalúan su desempeño, o cómo los formadores de formadores de docentes en EIB, podrán valorar estos criterios e incorporarlos en el proceso formativo. Futuras investigaciones debieran asumir la tarea de aproximar algunas. 


\section{Notas}

${ }^{1}$ El Asesor Cultural es una persona mapunche elegido por la comunidad según criterios de saberes culturales y lingüísticos, que cumple el papel de mediador entre la escuela y el lof che -comunidad parental (Durán et al. 2007).

${ }^{2}$ La expresión mapunche refiere, por un lado, a la autodenominación del pueblo hoy conocido como "mapuche", nombre que surge hacia mediados de 1900; por otro lado, como categoría lingüística diferenciadora entre lo propio y lo ajeno.

${ }^{3}$ El movimiento mapunche pos reduccional asume, por lado, una estructura organizacional de tipo occidental y, por otro lado, junto a la reivindicación territorial plantea demandas en el campo educacional escolar y políticas de enseñanza de la lengua mapunche en las escuelas. En el período de autonomía pre-reduccional, el pueblo mapunche tenía el control cultural de su lengua y educación y, en efecto no se requieren de políticas estatales. 


\section{Bibliografía}

Aguado, Teresa (2003), Pedagogía intercultural, McGraw-Hill / Interamericana de España, S. A. U. Madrid.

Alliaud, Andrea \& Antelo Estanislao (2009), “Iniciarse a la docencia. Los gajes del Oficio de enseñar”, en Profesorado. Revista de currículum y formación del profesorado, en línea: http://www.ugr.es/ recfpro/ rev131ART6.pdf

Augusta, Félix ([1916]/1991), Diccionario Araucano: Mapuche - español, Español- mapuche, Editorial Kushe, Temuco.

Avalos, Beatrice; Cavada, Paula; Pardo Marcela \& Sotomayor Carmen (2010), "La profesión docente: temas y discusiones en la literatura internacional", en Estudios Pedagógicos XXXVI, N 1: 235-263. Extraído: febrero 2014, en línea: http://www.scielo.cl/scielo.php?pid=S071807052010000100013\&script=sci_arttext

Báez-Jorge, Félix \& Amado Rivera (1983), “La educación Bilingüe-Bicultural: ¿Encrucijada de las lealtades étnicas y los conflictos de clases?”, en Nemesio Rodríguez, Elio Masferrer \& Raúl Vargas (Eds.), Educación, etnias y descolonización en América latina, UNESCO, México, Vol. 1, pp. 265-280.

Baronnet, Bruno (2008), “La Escuela Normal Indígena Intercultural Bilingüe “Jacinto Canes”: Movilización étnica y autonomía negada en Chiapas”, en Revista TRACE, N053, pp. 100-118.

Bourdieu, Pierre (2007), El sentido práctico, Siglo XXI editores, Buenos Aires.

Catriquir, Desiderio \& Teresa Durán (2007), “Kimeltuwün zugu: Modelo educativo mapunche”, en Teresa Durán, Desiderio Catriquir \& Arturo Hernández (Comps.), Patrimonio cultural mapunche. Derechos sociales y patrimonio institucional mapunche, Universidad Católica de Temuco, Temuco, Vol. III, pp. 443-454.

Catriquir. Desiderio (2004), Desempeño profesional del profesor de Educación Básica intercultural en escuelas situadas en contextos interétnicos de la IX región de la Araucanía. Una lectura desde la visión de los actores, Tesis de Maestría, Universidad de la Frontera, Temuco.

Chiodi, Francesco (1990), “Capítulo II Guatemala”, en Francesco Chiodi (Comp.), La Educación indígena en América latina. México - GuatemalaEcuador - Perú - Bolivia, Abya-Yala, Quito, Tomo I, pp. 157-328.

Citarella, Lucas (1990), “Capítulo I, México”, en Francesco Chiodi (Comp.), La educación indígena en América latina, México - Guatemala - Ecuador - Perú - Bolivia, Abya-Yala, Quito, Tomo I, pp. 9-155. 
Comisión de Verdad Histórica y Nuevo Trato con los pueblos indígenas (2009), Informe de la Comisión de verdad histórica y nuevo trato con los pueblos indígenas ( $3^{\mathrm{a}}$ ed.), Pehuén Editores, Santiago de Chile.

Corporación Nacional de Desarrollo Indígena (CONADI) (1993), Ley indígena $N^{o} 19.253$. D. of. 5·10·1993. Santiago.

Cox, César \& Gysling, Jacqueline (2009), La formación del profesorado en Chile. 1842 - 1987, Ediciones Universidad Diego Portales, Santiago de Chile.

Cuenca, Ricardo (2007), “Hacia dónde va la formación docente en América latina”, en Ricardo Cuenca, Nicole Nucinkis, \& Virginia Zavala (Comps.), Nuevos maestros para América latina, Morata, Madrid, pp. 23-36.

Díaz, María (1996), Formas de enseñanza-aprendizaje del niño mapuche en la escuela y en la Familia-lof y en la escuela rural de Mijaweko. Tesis de Licenciatura en educación, Universidad Católica de Temuco, Temuco.

Durán, Teresa \& Nelly Ramos (1987), “Incorporación del español por los mapuches del centro sur de Chile durante el siglo XIX”, en Revista Lenguas modernas, $\mathrm{N}^{\circ} 14$, pp. 179-195.

Durán, Teresa \& Catriquir, Desiderio (2007), “Complejidad de los estudios avanzados formales en el tratamiento de la diversidad cultural: introducción a una metodología transcultural”, en Teresa Durán, Desiderio Catriquir \& Arturo Hernández (Comps), Patrimonio Cultural Mapunche, Vol. VII, pp. 247-282.

Durán, Teresa, José Quidel, Arturo Hernández \& Desiderio Catriquir (2007), "Propuesta académico-social de la EIB en la región de la Araucanía: Proyecto Piloto”, en Teresa Durán, Desiderio Catriquir \& Arturo Hernández (Comps), Patrimonio Cultural Mapunche, Vol. VII, pp. 195-206.

Durán, Teresa, Nelly Ramos \& Arnold Rockman (1989), “Modelos de educación indígena en Chile”, en Luis Enrique López \& Ruth Moya (Eds.), Pueblos indios, estados y educación, PEB-Puno, MEC-GTZ, Lima, pp. 87105.

Durán, Teresa, Desiderio, Catriquir \& Macerlo Berhó (2011), “Diversidad cultural e interculturalidad en una universidad del centro sur de Chile. Validando una categoría analítica”, en Revista Cuadernos Interculturales, $\mathrm{N}^{\circ}$ 17 , pp. 135-157.

Erize, Esteban (1960), Diccionario comentado Mapuche-español, Cuadernos del Sur, Buenos Aires.

Foerster, Rolf \& Montecino, Sonia (1988), Organizaciones, líderes y contiendas mapuches (1900-1970), Ediciones CEM, Santiago de Chile. 
Garcés, Fernando (2006), “La EIB en Ecuador”, en Luis Enrique López \& Carlos Rojas (Eds.), La EIB en América latina bajo examen, Plural Editores, La Paz, pp.111-183.

Gigante, Elba (2007), "Diversidad sociocultural y formación docente en México”, en Ricardo Cuenca, Nicole Nucinkis \& Virginia Zavala (Comps.), Nuevos maestros para América latina, Morata, Madrid, pp. 190-225.

Guarda, Gabriel (2001), Nueva Historia de Valdivia. Ediciones Universidad Católica de Chile. Santiago de Chile.

Guba, Egon \&e Lincoln, Yvonna (2002), "Paradigmas en competencias en la investigación cualitativa”, en, C. Denman \& J. A. Haro (Comps.), Por los rincones. Antología de los métodos cualitativos en la investigación social, El Colegio de Sonora, Sonora, pp. 113-145.

Hevia, Ricardo \& Hirmas, Carolina (2005), La discriminación y el pluralismo cultural en la escuela. Casos de Brasil, Chile, Colombia, México y Perú, OREALC/UNESCO, Santiago de Chile.

Huenchullán, Carolina (2007), “La institucionalización de la Educación Intercultural Bilingüe en Chile: Contexto, situación actual y desafíos”, en Teresa Durán, Desiderio Catriquir \& Arturo Hernández (Comps.), Patrimonio cultural mapunche. Derechos sociales y patrimonio institucional mapunche, Universidad Católica de Temuco, Temuco, Vol. II, pp. 207-226.

Imbernón, Francesc (1999), “Conceptualización de la formación y desarrollo profesional del profesorado”, en Vicente Ferres \& Francesc Imbernón (Eds.), Formación y actualización para la función pedagógica, Editorial Síntesis Educación, Madrid, pp. 25-34.

Inostroza, Gloria (1997), La práctica, motor de la formación docente. Dolmen Ediciones. Santiago.

Labaree, David (1999), "Poder, conocimiento y racionlaización de la enseñanza. Genealogía del movimiento por la profesionalidad docente”, en Ángel Pérez, Javier Barquín \& Félix Angulo (Eds.), Desarrollo profesional del docente, política, investigación y práctica, Akal textos Madrid, pp. 16-51.

López, Luis Enrique (1999), “Programa regional de formación de recursos humanos en Educación Bilingüe Intercultural”, en Nelly Escobar, Wolfgang Küper \& Teresa Valiente-Catter (Eds.), Fórum internacional de formación docente. Mirada desde su práctica formativa, Ministerio de Educación del Perú. GTZ, Cooperación Técnica Alemana, Lima, pp.149-160.

Ídem (2005), De resquicios a boquerones. La educación intercultural bilingüe en Bolivia, Plural Editorial, La Paz.

Llerena, Odalia (2011), Una mirada a la orientación profesional desde el 
enfoque histórico cultural en la educación superior actual, en línea: http:// www.eumed.net/rev/cccss/16/olc.html

Marcelo, Carlos (1999), Formación del profesorado para el cambio educativo. Ediciones Universitarias de Barcelona. Barcelona.

Marradi, Alberto; Archenti, Nélida \& Piovani, Juan Ignacio (2007), Metodología de las ciencias sociales, Emecé editores. Buenos Aires.

McLaren, Peter (1995), La escuela como un performance ritual. Hacia una economía política de los símbolos y gestos educativos, Siglo XXI editores. México.

Ministerio de Educación (MINEDUC) (2005), Identificación y descripción de contenidos culturales aymara, atacameño y mapuche, Ministerio de educación, Santiago de Chile.

Moya, Ruth (2007), “Formación de maestros e interculturalidad”, en Ricardo Cuenca, Nicole Nucinkis \& Virginia Zavala (Comps.), Nuevos maestros para América latina, Morata, Madrid, pp. 229-258.

Nucinkis, Nicole (2006), “La EIB en Bolivia”, en Luis Enrique López \& Carlos Rojas (Eds.), La EIB en América latina bajo examen, Plural Editores, La Paz, pp. 25-110.

Ídem (2007), “La formación de maestros en EIB en América Latina”, en Ricardo Cuenca, Nicole Nucinkis \& Virginia Zavala (comps.), Nuevos maestros para América Latina. Morata, Madrid, pp. 57-122.

Pérez, Ángel (1999), “El practicum de enseñanza y la socialización profesional de los futuros docentes”, en Ángel Pérez, Javier Barquín \& Félix Angulo (eds.), Desarrollo profesional del docente. Política, investigación y práctica, Akal Ediciones, Madrid, pp. 636-660.

Pérez, Esther \& Martínez, Fernando (2004), “Pedagogía y revolución. Entrevista a Paula Freire”, en Claudia Korol (Coord.), Pedagogía de la resistencia. Cuadernos de Educación Popular, Ediciones Madres de Plaza de mayo - América libre, Buenos Aires, pp. 25-45.

Reyes, Saúl y Bulmaro Vásquez (2008), "Formar en la diversidad. El caso de la escuela Normal Bilingüe Intercultural de Oaxaca (ENBIO)”, Revista TRACE, N 053, pp. 83-99.

Rubio, Fernando (2006), “La educación bilingüe en Guatemala”, en Luis Enrique López \& Carlos Rojas (Eds.), La EIB en América latina bajo examen, Plural Editores, La Paz, pp. 185-252.

Stake, Robert (1998), Investigación con estudio de casos, Ediciones Morata, Madrid. 
Polis, Revista Latinoamericana, Volumen 13, $N^{\circ}$ 38, 2014

Universidad Católica de Temuco (1993), Plan Curricular Pedagogía en Educación General Básica. Licenciado en Educación. Especialización en Educación Intercultural. Vicerrectoría Académica, Temuco.

Recibido: 15.05.2014

Aceptado: 29.11.2014 